\title{
SLAM POETRY COMO CONFRONTO NAS RUAS E NAS ESCOLAS
}

\author{
Caio Ruano da Silva ${ }^{1}$ \\ CRISTIANA LOSEKANN ${ }^{2}$
}

\begin{abstract}
RESUMO: O artigo apresenta a dimensão política do slam poetry como prática artística, que pode ser compreendida como manifestação social contestadora e que produz crítica institucional. Observa-se que essa prática tem sido progressivamente transposta para o espaço institucional escolar. O presente artigo foca na reflexão acerca desse processo em escolas do estado do Espírito Santo. Baseando-se no método de etnografia política, buscou-se, principalmente, compreender tanto o processo de transposição do slam para as escolas quanto o que ocorre com o seu potencial político nesse novo ambiente. Os resultados apontam que, mesmo com algumas descaracterizações, o slam mantém seu potencial político no ambiente escolar, na medida em que busca democratizá-lo.
\end{abstract}

Palavras-chave: Slam poetry. Práticas artísticas. Práticas educacionais.

\section{SLAM POETRY AS CONFRONTATION ON THE STREETS AND IN SCHOOLS}

\begin{abstract}
This paper presents the political dimension of slam poetry, an artistic practice that can be characterized both as a manifestation of social contestation, and as a production of institutional critique. It is observed that this practice has been, progressively, transported to the institutional school space. This paper focuses on reflecting about this process in schools located in the state of Espírito Santo, Brazil. Based on the political ethnography method, the aim was understanding both the process of transposing slam poetry to schools, and what occurs to its political potential in this new environment. Results show that, even facing a few adaptations, the slam maintains its political potential in schools, since it also aims to democratize this new environment.
\end{abstract}

Keywords: Slam poetry. Artistic practices. Educational practices.

\footnotetext{
Trabalho desenvolvido como parte do projeto de pesquisa “Transformações do Ativismo no Brasil: Junho de 2013 em Perspectiva Comparada", financiado pelo edital 012/2015 da CAPES, "Memórias Brasileiras/Conflitos Sociais" (n. 88881.130844/2016-01).

1.Instituto Federal do Espírito Santo - Coordenadoria de Administração - Guarapari(ES), Brasil. E-mail: caio.silva@ifes.edu.br

2.Universidade Federal do Espírito Santo - Departamento de Ciências Sociais - Vitória (ES), Brasil. E-mail: cristianalosekann@gmail.com
} 


\section{SLAM POETRY COMO CONTESTACIÓN EN LAS CALLES Y EN LAS ESCUELAS}

RESUMEN: El artículo presenta la dimensión política de la poesía slam como práctica artística, que puede entenderse como manifestación social confrontadora y que produce una crítica institucional. Se observa que esa práctica ha sido, progresivamente, transpuesta al espacio escolar institucional. Este artículo enfoca en la reflexión sobre este proceso en escuelas del estado de Espírito Santo, Brasil. Basándose en el método de etnografía política, se buscó comprender tanto la transposición del slam a las escuelas cuanto lo que sucede con su potencial político en ese nuevo ambiente. Los resultados indican que, aunque hayan modificaciones, el slam mantiene su potencial político en el ambiente escolar, puesto que busca democratizarlo.

Palabras-clave: Poesía slam. Prácticas artísticas. Prácticas educativas.

\section{Introdução}

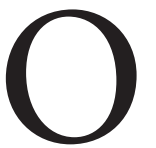

slam poetry surgiu na década de 1980, em Chicago, tendo como seu principal e mais reconhecido precursor o poeta Marc Kelly Smith. Desde então, a modalidade se popularizou e iniciou o que se pode chamar de um processo de difusão e internacionalização. De acordo com sua entidade oficial, há atualmente 112 slams registrados nos Estados Unidos e no Canadá (POETRY, 2019). Além disso, muitos slams não são registrados pela entidade, tanto nesses países quanto em diversos outros ao redor do mundo. Exemplos de países com poetry slams discutidos pela literatura acadêmica são Brasil (NEVES, 2017), Espanha (CULLELL, 2015), França (POOLE, 2007) e Gabão (ATERIANUS-OWANGA, 2015), entre outros. No entanto, em que consiste o slam poetry?

Para um significado operacional, o presente estudo apoia-se, inicialmente, no livro de Smith e Kraynak (2009), assim como na obra de Glazner (2000), produtor do primeiro torneio nacional dessa categoria, realizado em 1990, nos Estados Unidos, país de origem da modalidade. Smith e Kraynak (2009) afirmam que a base do slam poetry está em cinco elementos principais: poesia, performance, competitividade, interatividade e comunidade.

Poesia pode parecer o mais óbvio e central dos elementos, porém, como afirmam Smith e Kraynak (2009), não se trata de ver quem é o poeta mais brilhante. O slam poetry surgiu para resgatar a poesia, que, no entendimento desses autores, era uma arte morta. Os autores entendem que declamar uma poesia em público era normalmente visto como algo ridículo, de modo que o objetivo do slam era elevar novamente o poeta ao patamar de outros artistas performáticos, como músicos e atores. No universo literário e acadêmico, a ênfase no texto praticamente proíbe uma interpretação por quem o declama, o que, segundo eles, gera desinteresse do público em geral por leituras de poesia. Assim, para efeitos de avaliação, no slam, a performance do poeta é levada em consideração: sua interpretação, entonação e corporeidade.

Como ressaltado anteriormente, o slam poetry é uma modalidade competitiva. As regras normalmente envolvem um limite de três minutos para a apresentação de cada artista, a utilização de textos autorais e a proibição do uso de qualquer acessório ou equipamento. Os jurados são membros da plateia selecionados pouco antes do início do evento. O público é incentivado a se manifestar perante as performances e a aplaudir ou vaiar as notas dos jurados de acordo com sua concordância ou discordância. Assim, interatividade é outro fator central. 
Contudo, apesar do elemento competitivo, para Smith e Kraynak (2009), os slams são eventos agregadores, locais de interação, nos quais a poesia não se define ou é julgada pelos padrões impostos por uma elite. Tão importantes quanto qualquer outro elemento são as relações que se criam e se fortalecem nesses eventos. Daí o potencial do slam poetry de instituir, ao seu redor (ou ser em si), uma comunidade.

Embora, em vários lugares do mundo, os poetry slams ocorram em bares e cafés e, no Brasil, normalmente aconteçam em ruas, praças ou centros culturais, tem se observado, em vários países, a transposição dessa prática social para instituições de ensino. Desse modo, este estudo busca compreender como tem transcorrido a expansão do slam poetry desses espaços originários, como prática social, para o espaço institucional escolar. Como tem sido esse processo de inserção e como se transforma a potência do slam poetry nesse novo espaço? São essas as perguntas norteadoras do presente artigo. A seção seguinte apresenta os procedimentos metodológicos utilizados no intuito de responder a essas questões.

\section{Procedimentos Metodológicos}

O lócus empírico do presente estudo são escolas de Ensino Médio do estado do Espírito Santo. A escolha por esse estado se justifica por dois fatores. O primeiro se refere ao fato de o movimento de slams nesse estado ser relativamente recente, tendo começado em 2015, e concentrar-se na região da Grande Vitória, com poucos slams estabelecidos (seis, até o momento da escrita deste artigo, sendo a maior parte deles criada nos últimos dois anos), em comparação com movimentos de capitais maiores, como São Paulo e Rio de Janeiro ${ }^{1}$. Tanto o fator temporal quanto a concentração territorial se demonstraram vantajosos, na medida em que permitiram um mapeamento preciso dos sujeitos presentes na "cena", facilitando a observação de suas ações e interações, inclusive no que se refere à transposição do slam para as escolas do estado. Além disso, apesar de ser um movimento recente no Espírito Santo, o estado foi um dos primeiros do país a realizar torneios interescolares, sendo a primeira edição do Slam Interescolar realizada em 2017. O segundo fator decisivo para a escolha da localidade foi a acessibilidade aos dados.

Dessa maneira, com base no trabalho de Auyero (2012), buscou-se realizar uma etnografia política. Nesse método, utiliza-se uma forma de investigação baseada na "observação próxima, no terreno, de atores e instituições políticas em tempo e espaço reais, onde o investigador se insere próximo (ou dentro) do fenômeno a ser estudado, para detectar como e por que os atores na cena atuam, pensam e sentem" (AUYERO, 2012, p. 20). Nesse sentido, o trabalho tanto apresenta a descrição de um fenômeno social ainda pouco conhecido quanto propõe caminhos analíticos que podem ajudar a compreender o cruzamento entre práticas artísticas, espaço público e escola, ao analisar o deslocamento de práticas artísticas espontâneas que ocorrem no espaço público para dentro da instituição escolar.

Os dados que fundamentaram esta pesquisa foram coletados por meio de observação participante em dez eventos de slam realizados no estado do Espírito Santo, incluindo os torneios interescolares de 2018 e 2019, bem como treze entrevistas com catorze sujeitos diretamente ligados ao movimento. O número de entrevistados é maior do que o de entrevistas pelo fato de que, em uma ocasião, realizou-se uma entrevista coletiva.

Ao todo, foram entrevistados dez professores de oito escolas diferentes - sete públicas e uma filantrópica -, três slammasters (organizadores de slams; uma das entrevistadas, Dani, além de ser professora de uma dessas escolas é também a organizadora do Slam Nísia) e dois slammers/alunos, que competem tanto em suas escolas como em "slams de rua". Nossos dados revelam que o slam poetry foi inserido nas escolas por 
iniciativa desses professores, que já conheciam os slam como prática social. Em todos os casos, houve contato com o slammaster John Conceito, que percorre diversas escolas no estado com o objetivo de apresentar o slam poetry. Foi a partir dessa interação que essas escolas organizaram seus campeonatos internos e inscreveram seus campeões nos torneios interescolares do estado.

As entrevistas foram transcritas e os dados foram categorizados para análise de conteúdo. As categorias de análise foram definidas a priori, com base na literatura revisada, sendo elas: 1) vivência com o slam poetry (análise das experiências com a modalidade e dos significados do slam poetry); 2) características do slam poetry (tipos de público, estilos e temas de poesias e performances etc.); 3) processo de transposição do slam para as escolas (maneira, intenção, apoio, resistência, fatores facilitadores, dificuldades, reações dos profissionais e dos estudantes etc.); e 4) características do slam na escola (regras, estilos e temas de poesias e performances, participantes etc.). A partir de determinado ponto, passou-se a observar uma saturação nos resultados, o que apontou para a suficiência de dados para a realização do trabalho.

\section{O Sujeito Político no Slam Poetry}

Somers-Willett (2005) afirma que uma das características mais definidoras do slam é a presença de performances de identidade. A autora aponta que performances desse tipo são cada vez mais comuns no palco do National Poetry Slam, competição de nível nacional realizada anualmente nos Estados Unidos. Assim, no slam, a proclamação da identidade parece ser parte crucial de um poema de sucesso, e a performance é o instrumento que faz o poema soar verdadeiro ou falso para determinada plateia (SOMERS-WILLETT, 2005).

Todavia, ao premiar poetas pela autenticidade nas performances de identidades marginalizadas, de modo geral, o que é considerado autêntico pode ser, na verdade, construído por esse processo de recompensa; ou seja, o sujeito político surge como processo de identificação e reconhecimento. Como escreve SomersWillett (2005, p. 56), "resumidamente, slams podem gerar as próprias identidades que os poetas e o público esperam ouvir". Assim, o slam se torna um espaço de formação de identidades e, consequentemente, de formação de uma identidade política.

A análise das performances poéticas sugere que essa identidade política é composta tanto pelo caráter de protesto contra aspectos e membros da política institucional quanto pela articulação da luta de diversas minorias. Tons passionais e de protesto são comuns, e muitos poetas tratam o slam como palanque político, alguns quase exclusivamente (SOMERS-WILLETT, 2005), o que confere aos slammers um status de ativistas, mesmo que apenas manifestado em forma discursiva. Seguem alguns exemplos encontrados na literatura da área.

Ao analisar o contexto espanhol, Cullell (2015) afirma que, muitas vezes, as poesias dos torneios de slam se referiam à crise econômica e à insatisfação com o governo. Em relação ao slam na França, Poole (2007) destaca que não existe um tipo específico de poeta, tampouco um tema específico de poesia, porém denúncias de injustiças e desigualdades sociais são temas característicos de slams. Ainda de acordo com a autora, os slams retratam muitas queixas do século XXI, ao abordarem temas como a violência, o consumismo, o racismo e o isolamento social. Aspectos semelhantes existem em Nova York, onde poetas apresentam textos sobre racismo, sexismo, violência policial, exploração e opressão da classe trabalhadora, entre outros (BELLE, 2003).

No cenário brasileiro, Neves (2017, p. 104) destaca, como temáticas poéticas desses eventos, "críticas às desigualdades sociais, ao preconceito racial, à violência contra a mulher, à homofobia, à transfobia”. De acordo com Neves Neves (2007, p. 92), os slams dão voz a poetas da periferia, que geralmente retratam nas 
poesias temas de seu cotidiano, "sempre de teor crítico e engajado, que requerem a escuta, a reflexão e a politização de seu público-ouvinte”.

Nossas investigações também apontam nessa direção. Observamos a reincidência dos mesmos temas principais nos eventos do Espírito Santo. Além disso, os slammasters que entrevistamos no estado possuem ideologias que retratam uma confluência de forças entre causas sociais, conforme demonstrado a seguir:

Pra mim, eu tenho uma filosofia de vida que, quanto menor a causa, quanto menor a minoria, mais importante ela é. Tem até uma poesia que eu fiz aqui em cima do morro com um brother, que diz: "meu filho vai ser tão ignorante quanto eu, ele vai lutar por causas ainda menores do que as minhas" [...] As poesias minhas que estão tendo mais repercussão, que eu gravei, são poesias que falam sobre o racismo. Tem poesias que falam também sobre o machismo, que é muito forte (Bantu do Gueto).

Mas aí, são essas as causas: a mulher negra, o marginalizado da periferia e a população LGBT [...] Eu não sou negra, nem de periferia. Mas é aquela causa ali que eu gosto de lutar (Dani).

Eu acho que toda a luta é importante. E talvez você me veja um dia falando sobre a dificuldade de ser preto e da favela, qualquer coisa. Mas eu acho que toda luta é importante (John).

Percebe-se um cruzamento de causas mais frequentes (contra o racismo, machismo e homofobia), espaços (morro, favela, periferia) e sujeitos (minoria, negros, mulheres, LGBT). No processo de constituição da identidade política por meio do slam, vale notar, como fica evidente em uma das falas, que nem todos os participantes são os sujeitos que sofrem os problemas sociais em questão, mas aqueles que constroem uma identificação com essas causas.

Nesse sentido, o processo de constituição de uma identidade política se dá tanto pelo lugar de fala quanto pela construção de uma projeção desse lugar da fala pelo outro. Reconhecemos, portanto, que há diferença na identidade performada daqueles sujeitos que falam a partir de uma experiência encarnada de ser negro, negra, da periferia, gay etc. Essa experiência encarnada pode ser entendida no sentido da "experiência vivida do negro", em Fanon (2008), bem como na noção de lugar de fala de Ribeiro (2017). Isso, porém, não significa que não ocorra um processo real de identificação por meio do slam em sujeitos que não estão submetidos às mesmas experiências de opressão. Na verdade, o próprio processo de publicização das causas pela poesia é capaz de produzir esse efeito. A questão é haver uma diferença, percebida e tensionada pelos membros do slam, conforme pudemos observar.

Nesse sentido, tanto o processo interno de subjetivação e identificação política quanto a passagem das ruas para as escolas caracterizam o slam como prática permeada por tensionamentos e confrontos. Constitui-se, assim, um espaço para experienciar antagonismos. O posicionamento, nessa encruzilhada de lutas, faz com que defendamos a ideia de que o slam poetry é manifestação daquilo que Mouffe (1993) teorizou como meio para a democracia radical e plural. Tendo, então, como objetivo o aprofundamento da democracia, Mouffe (1993) coloca como necessária a conexão entre as diversas lutas da democracia. Nas palavras da própria autora, "[t]al esforço requer a criação de novas posições subjetivas, que permitam uma 
articulação comum, por exemplo, entre antirracismo, antissexismo, e anticapitalismo" (MOUFFE, 1993, p. 18, tradução nossa).

Para Mouffe (1993), esses esforços não convergem de maneira espontânea e, para estabelecer equivalências democráticas, um novo "senso comum" é necessário, que transforme a identidade dos diferentes grupos de maneira que as demandas de cada um desses se articulem. Contudo, "não se trata de estabelecer uma mera aliança entre esses interesses, mas de modificar a própria identidade dessas forças" (MOUFFE, 1993, p. 19, tradução nossa). O slam poetry pode ser considerado um processo de identificação política, por meio do qual se criam equivalências dessas forças. Ao valorizar a pluralidade, o slam contesta o essencialismo, que nutre a visão de natureza humana indiferenciada propagada pelo Iluminismo, de acordo com Mouffe (1993). Parte da potência política do slam encontra-se nessa luta para proporcionar voz às minorias, uma luta por igualdade. A outra parte reside na possibilidade de expressar aquilo que se deseja.

É esse o movimento que tem se expandido de modo crescente para o espaço institucional escolar em vários países do mundo. No entanto, é, de certa maneira, uma ingenuidade partir do pressuposto de que a relação de influências entre slam poetry e escolas é uma via de mão única. Assim, torna-se interessante explorar a influência que um traz sobre o outro. De modo geral, há um entendimento de que o slam é um espaço que busca a liberdade no que se refere a palavras, gestos, posturas, expressões e emoções. Mesmo preso a suas convenções e noções sobre o (in)aceitável, o slam poetry ambiciona ser um espaço permissivo. O espaço escolar, pelo contrário, exige normalmente um vocabulário específico e um código de postura particular, que envolve controle das emoções e das expressões.

Não desejamos aderir, de maneira inquestionável ou sem as devidas considerações, a uma visão institucional e de educação pautada unicamente no poder disciplinar foucaultiano. Todavia, como estamos ainda mais distantes de negar a existência desse poder nas relações educacionais dos contextos estudados, cabe perguntar como, ao ser institucionalizado como prática escolar, o slam é afetado, e que questões se colocam em termos de seus potenciais políticos. Buscando um embasamento para essas discussões, a próxima seção consiste na revisão do que a literatura acadêmica tem observado e relatado sobre a interação do slam em ambientes de ensino.

\section{Os Slams Criam e Ocupam Espaços de Educação}

O slam poetry não pode ser considerado uma iniciativa inédita na democratização da arte ou no seu uso para a contestação política no Brasil. Nesse sentido, uma referência histórica é fornecida por Sposito et al. (1987), ao descreverem o Movimento Popular de Arte (MPA) em São Paulo. Esse movimento atuou a partir do ano de 1978, voltado para a periferia e composto por artistas performáticos diversos, principalmente, músicos, atores e poetas (SPOSITO et al., 1987).

Ainda de acordo com os autores, a partir de 1984, o MPA passou a fazer uma "ocupação cultural" em escolas públicas. Além da realização de eventos artísticos no espaço escolar, o grupo também incentivava a abertura da escola para que alunos e membros da comunidade pudessem pensar e discutir a questão da cultura. Assim, observa-se que, mesmo anteriormente ao slam poetry, o espaço escolar já se mostrava atraente para interação com expressões culturais e artísticas populares, bem como interessado nela.

Exemplos mais atuais dessas interações envolvem a inserção da capoeira (AMARAL; SANTOS, 2015), do funk (AMARAL, 2011) e do rap (AMARAL, 2011; 2013) em escolas públicas brasileiras. É especialmente com essas duas últimas expressões que o slam poetry tem dividido o espaço escolar das periferias. Amaral (2011, p. 594) afirma que essas expressões (funk e rap) apresentam "forte ressonância 
com a diáspora afro-americana e afro-indígena-brasileira" - dimensão insuficientemente explorada pelos estudiosos das culturas juvenis, porém evidenciada nas produções artísticas dos estudantes. Sabemos, pela seção anterior, que esse é também um dos aspectos que se destacam na produção artística do slam como prática social, de modo que se torna interessante analisar a produção acadêmica acerca da transposição do slam para os espaços escolares a fim de observar que dimensões têm sido privilegiadas.

A discussão sobre o slam poetry na área da educação tem refletido, principalmente, sobre dois pontos. O primeiro refere-se ao impacto que a modalidade tem tido no público jovem e vice-versa. $\mathrm{O}$ segundo refere-se às aplicabilidades do slam como ferramenta de ensino, inclusive para além dos ambientes tradicionais de aprendizagem.

Exemplos internacionais desses ambientes extracurriculares são os Youth Slam and Spoken Word (YSSW), programas baseados em aprendizado centrado nos estudantes, com ênfase em poesia e performance, que buscam criar uma comunidade de poetas. Os YSSW tomam a forma de clubes pós-escola ao longo do ano ou projetos de curto prazo mais delimitados, e buscam atingir jovens desencantados pela poesia e pelo sistema de educação formal (GREGORY, 2013).

O trabalho de Fields et al. (2014) fornece um exemplo desse tipo de iniciativa. Os autores analisaram como jovens abordaram temas relacionados a juventude, sexualidade, saúde e direitos em poemas apresentados no Tucson Youth Poetry Slam (TYPS), no Arizona. A análise das poesias selecionadas nesse trabalho apontou a existência de padrões no discurso poético, que revelam engajamento e conhecimentos dos jovens sobre assuntos de interesse social. Gregory (2013) concorda com essa análise, ao afirmar que narrativas de transformação pessoal e política são comuns nos YSSW, uma vez que esses espaços propiciam a autoexpressão. Desse modo, esses se tornam espaços valiosos para grupos normalmente silenciados, como minorias e, de modo geral, jovens. "Isso desafia a percepção comum de que adolescentes não 'fazem' política, demonstrando como jovens têm utilizado a poesia para traçar sua própria agenda” (GREGORY, 2013, p. 128, tradução nossa).

À parte do aspecto político, outras aplicabilidades também são destacadas pela literatura na utilização do slam exclusivamente como ferramenta de ensino dentro de espaços formais de educação. Boudreau (2009) afirma que as experiências que as crianças têm com a poesia na escola geralmente envolvem recitação e memorização. Essas experiências são focadas em poesia como gênero, na sua estrutura e no estudo de poemas celebrados do ocidente. Ao romper com essas questões, as características do slam o fazem um poderoso veículo para ensinar crianças.

Poole (2008) também destaca a capacidade do slam de retratar culturas e, assim, sugere-o como ferramenta para o ensino de línguas estrangeiras. Pela variedade de estilos e tópicos, tal autora acredita que o slam seja uma boa escolha para os professores, não apenas por sua base linguística, mas também por representar a cultura popular e oferecer imagens e sons atualizados (up-to-the-minute) da sociedade. (POOLE, 2008). Já Brown (2011) relata sua experiência como professora da disciplina de literatura inglesa da Texas A\&M University, uma universidade não tradicional. Para enfrentar dificuldades corriqueiras ao lecionar o gênero poético, ela resolveu criar um "bad slam" (slam ruim) em sua aula. A competição era pela criação do poema mais ridículo. Esse slam auxiliou os estudantes a refinarem sua compreensão literária quanto à qualidade de trabalhos canônicos e não canônicos, além de aumentarem sua apreciação pela forma e pelo gênero poético.

No Brasil, em uma pesquisa que buscava compreender os atos responsivos dos estudantes da zona rural do estado de São Paulo diante de uma situação de criação, circulação e apreciação estética de textos poéticos, Viana (2018) observou a tensão existente no ambiente escolar com a proposta e a realização de um slam. De um lado, diretores e outros representantes do status quo receavam as críticas do slam; do outro, 
professores e alunos desejavam se expressar de modo independente, inclusive abrindo espaços para críticas acerca do próprio sistema educacional.

Observamos que promover espaços discursivos genuínos aos alunos, dentro do ambiente escolar, esbarra em questões de diversas ordens: na imposição de um conteúdo, material e um fazer pedagógico, pela Secretaria de Educação do Estado, que prioriza um ensino engessado e tecnicista; no preconceito linguístico, promovido por agentes da manutenção da ordem vigente dentro da escola, que dificultam propositivas mais libertadoras de trabalho (VIANA, 2018, p. 127-128).

Observa-se que, nos casos anteriormente mencionados, assim como na maior parte dos casos relatados, o slam poetry foi levado à sala de aula por iniciativa dos próprios professores.

Em uma rota diferente, na província de Québec, no Canadá, o slam foi incluído pelo governo no plano de estudos de alunos secundaristas desde 2009. Os estudos de Émery-Bruneau e Yobé (2014) e Émery-Bruneau (2015) buscaram compreender essa transposição do slam como prática social para objeto e ferramenta de ensino. As autoras observaram que, mesmo com sua inclusão curricular, o slam ainda era pouco conhecido pelos docentes e acabava sendo ensinado meramente para cumprir a avaliação de uma produção acadêmica. Tais autoras concluíram que a distância entre a prática social de referência e a prática escolar se dá porque, na primeira, o objetivo é obter uma reação positiva do público, enquanto, na segunda, busca-se apenas realizar uma tarefa para satisfazer os critérios de avaliação determinados pelo professor. Ademais, a discrepância encontra-se no fato de que, na prática social, a imagem (espaços e performances) é tão importante quanto o texto, enquanto, no plano escolar, a importância está somente no texto e na expressão oral.

De modo geral, as pesquisas revisadas possuem valor pela reflexão teórica ou pelos relatos empíricos acerca da utilização do slam poetry no contexto educacional. No entanto, seu conjunto apresenta maior valor descritivo do que comparativo, sendo esses relatos de contextos socioculturais distintos e, principalmente, provenientes de experiências educacionais de níveis diversos (educação infantil, educação fundamental, nível universitário, clubes extracurriculares etc). Essa, porém, é a base da qual dispomos no momento, bem como o corpus de trabalhos que buscamos ampliar com esta pesquisa, cujos resultados encontram-se na próxima seção.

\section{A Entrada do Slam Poetry em Escolas do Espírito Santo}

Os dados que levantamos sobre a entrada dos slams em escolas do Espírito Santo nos apontam três questões analíticas centrais sobre a institucionalização via escola de uma prática artística construída, originalmente, como transgressora e não institucional. São elas:

i. Adesão/oposição na inserção;

ii. Aplicabilidades do slam poetry como ferramenta/objeto de ensino;

iii. Potencial político do slam nas escolas.

Em relação ao primeiro ponto, foram variadas as reações da comunidade escolar às iniciativas de inserção do slam poetry. Como exemplo de abertura e incentivo, destaca-se o caso da escola na qual lecionam 
as professoras Camila, Islene e Daliene. Nesse caso, além do engajamento de professores de outras áreas, houve também envolvimento da direção, que conseguiu, junto à comunidade, prêmios para os alunos vencedores.

A gente não sentiu resistência nenhuma da escola nem do grupo de professores em relação ao slam [...] Não teve resistência e teve colaboração de quem quis colaborar (Daliene).

As escolas nas quais lecionam Dani, Maria Felicidade, e Wagner também apresentaram postura similar em relação ao slam poetry. Chama atenção que, no caso das quatro escolas citadas, a equipe (professores, pedagogos e diretores) já era atuante em outras formas de produção artística, dentro e fora da sala de aula.

Porque a gente estava "como é que o sarau tomou o lugar dos jogos escolares?" Mas aí a gente foi vendo que o professor de matemática, por exemplo, ele ensina com rap. Ele sai da sala e já fala pra mim "eu fiz isso, isso e isso". Aí eu já entro com inglês com o gancho do que ele falou. Eu saio da sala, entra o de português. Eu falo "eu fiz isso, isso e isso, e parei aqui". Aí ele já entra com o gancho. Então, era uma corrente de professores que abraçava mesmo essa causa da literatura, dava a sua aula, mas a literatura tinha um espaço bem-guardado, bem-cuidado na aula de cada um. [...] O professor de geografia falava "ah, vou falar de Banksy, o grafiteiro". A gente combinava no dia a dia, no improviso, mas aí acabou nesse resultado. E a direção acatou muito fácil [o slam], a direção deixou livre. E as escolas ao redor da nossa foram contaminadas, porque o aluno espalha (Dani).

Assim como a preexistência de outras formas de produções e eventos artísticos mais conhecidos e, talvez, mais “palatáveis", a localização das escolas em comunidades nas quais projetos e produções artísticas já eram algo comum pareceu naturalizar a inserção do slam no ambiente escolar em alguns casos.

Apresentei para os alunos e comuniquei à coordenação e à diretoria que eu estava trabalhando em um projeto de poesia falada. Contei um pouco da história da poesia slam, o impacto que ela tem na sociedade. Eles ficaram totalmente interessados e lembraram desse projeto Odara [projeto social mais amplo da comunidade] (Wagner).

Elas [alunas] já frequentavam batalha de rima. Assim, lá em Terra Vermelha tem evento literário de segunda a segunda. Só você notar. Pode ser batalha, pode ser slam, pode ser sarau, mas sempre tem. Então, é muito comum para elas dentro da periferia chegar e falar. "Ah, você vai na batalha hoje?" "Vou." "Você vai no slam hoje?" "Vou" "Sarau?” "Vou" (Dani).

No entanto, foi em contexto comunitário semelhante que ocorreu o principal caso de resistência ao slam poetry relatado nas entrevistas.

Não fornecem o espaço físico para que você tenha esse tipo de momento, esse tipo de atividade com os alunos. Perseguição por parte da coordenadora, assédio moral por parte da diretora. Porque eles não entendem que aquilo ali é mais do que uma balbúrdia, sabe? Que aquilo ali não são pessoas desocupadas que estão ocupando o espaço escolar pra dar mais trabalho para a coordenadora, que vai precisar olhar mais vinte alunos que estão na escola, mas não estão 
no horário de estudar. Então, o sistema buscou me derrotar muito nesse momento, e houve um momento em que eu perdi a minha saúde mental. Aí eu pedi afastamento e depois pedi remoção. Eu trabalho em outra escola hoje em dia [...] Aí, nessa nova escola onde eu trabalho agora, também tive dificuldades. Então, quando eu cheguei nesse novo posto de trabalho, a primeira coisa que aconteceu comigo foi o diretor me chamar para uma reunião na sala dele, só eu e ele, e falar “olha, aqui nessa escola não trabalhamos com arte”. Essa foi minha primeira reunião com o diretor, na primeira semana que eu cheguei na escola (Eloá).

Quando indagada sobre qual acreditava ser a raiz dessa resistência, a professora a atribuiu às diferenças identitárias entre membros que ocupam as posições pedagógicas das escolas e as populações das comunidades em que elas estão inseridas. Essa fala é, de certo modo, relacionada com o depoimento do professor Cristiano, que afirma existir preconceitos nas escolas em relação a manifestações culturais oriundas da periferia.

Todavia, além da explicação que atribui a resistência ao slam a diferenças identitárias pautadas, principalmente, na classe social, não se pode ignorar também a ameaça que esse tipo de iniciativa significa ao poder disciplinar que rege as instituições de ensino. É preciso dizer que as experiências com o slam nas escolas foram diferentes entre si. Por vezes, ocorreram em uma turma específica; em outros casos, envolveram a escola inteira. Fatores como esse fazem variar quão confrontador o slam pode ser ao poder disciplinar. Contudo, tomando Foucault (1999) como referência para a definição desse poder, é possível observar uma série de maneiras por meio das quais o slam pode desafiá-lo.

Ao ressignificar o uso do espaço físico escolar, promovendo comunicações potencialmente perigosas e agrupamentos por afinidades, o slam desarranja o espaço serial e as localizações funcionais característicos das disciplinas. Nessa mesma perspectiva, o slam desloca o conhecimento especializado do mestre para o julgamento democrático do público. A adesão ao slam é espontânea e sua produção não requer vigilância. Por se tratar de uma atividade criativa, sua produção pode ser originada do ócio e não precisa necessariamente respeitar horários. Aliás, de acordo com a fala da professora Eloá, o slam "desarranja" os horários, ao levar estudantes para a escola fora dos seus horários estabelecidos. Em contraponto direto ao poder disciplinar, o slam não apresenta compromisso com a utilidade econômica dos corpos: liberta-os de uma ergonomia planejada e atiça seu potencial político, retirando-os de um estágio de submissão e docilidade. De modo geral, o slam dentro da escola desafia o controle e a hierarquia e, talvez por isso, possa ser visto como desordeiro por parte de alguns diretores e coordenadores.

Mesmo assim, diferentemente do caso relatado por Viana (2018), o que se observou foi que, na maior parte dos casos, a inserção do slam poetry foi bem-vinda. Fatores que parecem influentes para a adesão ao slam são: a cooperação entre os professores; a confiança da direção ao proporcionar liberdade para os professores trabalharem com seus projetos; a tradição interna da escola de realizar atividades artísticas diversas; e a inserção das escolas em comunidades nas quais ocorrem projetos culturais. De todo modo, o caráter exploratório da presente pesquisa permite colocar esses fatores apenas como elementos que possivelmente auxiliam a aceitação do slam no ambiente escolar. Embora possam significar um ponto de partida para o pesquisador que futuramente deseje aprofundar-se nessa questão, no presente estudo, esses fatores mais servem para contextualizar os casos e levantar algumas reflexões pontuais, como acerca do potencial antagônico do slam.

Em relação ao segundo ponto de discussão - aplicabilidades do slam como ferramenta/objeto de ensino -, os relatos dos entrevistados apontam diversas possibilidades oriundas da inserção do slam na escola. Essas potencialidades variam do desenvolvimento dos estudantes (pessoal e grupal) às articulações com conteúdos das disciplinas, passando por aspectos do âmbito institucional e da relação entre escola e 
comunidade. No geral, os professores também observaram que o slam foi capaz de promover reflexões sobre o papel dos alunos na escola, de aumentar seu engajamento nas aulas, além de incentivar outras iniciativas no campo artístico dentro da escola, conforme nota-se nas entrevistas a seguir:

A primeira competição que teve em sala de aula foi uma menina que ganhou. Inclusive, a turma estava começando a ficar dispersa e essa menina fez uma poesia ali de conscientização da turma, falando que aquela escola que os alunos estavam fazendo era uma coisa prejudicial e que todos deveriam pensar nas atitudes e tal. $\mathrm{E}$ os mesmos que estavam bagunçando ali na hora começaram a se atentar, votaram, levantaram notas boas (Wagner).

Meus alunos têm se engajado muito mais na participação, ter voz ativa [...] E foi muito interessante que essa abertura fez com que, por exemplo, na semana da consciência negra, minha turma fizesse uma música com o menino que ganhou o slam. Ele fez uma parte e ele engajou a turma inteira para fazer uma música (Professora) ${ }^{2}$.

Nesse sentido, destaca-se a fala de Hooks (2017, p. 34), para quem "a pedagogia engajada, necessariamente valoriza a expressão do aluno" e busca o entusiasmo, em vez do tédio. Observou-se que o slam foi articulado com vários conteúdos já presentes no currículo regular. Os relatos a seguir refletem a diversidade de maneiras com que os professores utilizaram o slam de modo instrumental, no intuito de trabalhar outras questões da área de linguagens.

Eu acho que o slam tem sido uma das estratégias que eu tenho usado para fazer com que os meninos descubram novas linguagens, possam descobrir a língua portuguesa, consigam se empoderar [...] Então, eu pego uma palavra, peço para eles verem o significado. Principalmente quando a gente estava vendo essa parte de ortografia (Professora).

A primeira vez que eu apresentei para uma turma, no final do ano passado, e eu usei para o Barroco. Eu citei algo parecido assim "o slam é a boca do inferno dessa geração". Eles começaram a prestar atenção. Naquele ano, eu tive um bom desenvolvimento. Eles tiveram um interesse maior, porque o Barroco normalmente eles têm desinteresse em aprender (Cristiano).

A gente vai relacionando com alguma coisa ali de experiência de vida e de conteúdo também. Aí falei da Epopeia, da importância das narrativas que mostram a trajetória do homem e ele vencendo obstáculos. E um pouco da história desse tipo de narrativa (Wagner).

Esses relatos confirmam os posicionamentos de autoras como Boudreau (2009) e Brown (2011). Assim como em outras localidades, o slam poetry nas escolas do Espírito Santo é utilizado como estratégia para reduzir barreiras, ao tratar de poesia e literatura, e melhorar a relação dos alunos com a linguagem. Além disso, relatos como o do professor Wagner, anteriormente citado, demonstram o objetivo do slam quanto à valorização do que é rico em material poético dentro da vivência dos próprios alunos. Essa redução das barreiras entre escola e comunidade passa também pelo reconhecimento de alunos que antes não manifestavam seu potencial no espaço escolar, apenas nas ruas ou de forma privada. 
Tinha alguns meninos que participavam de slam, só que ninguém sabia. As professoras de português não sabiam, não sabiam nem o que era [...] Teve uma menina que ela nunca... ela escreve poemas brilhantes, mas ela nunca teve a coragem de expor (Professora).

Então, eles fizeram poesias ali, trouxeram para dentro da escola. Meninos que eu nem imaginava que escreviam (Maria Felicidade).

O próprio professor não conhece o aluno que escreve nas escolas, entendeu? É uma relação assim bem... e os alunos parecem que estavam ansiosos por essa pergunta e o professor não fazia (Dani).

A possibilidade de (re)conhecer os estudantes que o slam oferece ao ambiente escolar não se restringe aos seus talentos poéticos e performáticos. Uma vez que os textos de slam muitas vezes refletem aspectos identitários e situações das vivências de seus autores, no contexto em que os autores são estudantes, torna-se possível conhecê-los mais profundamente, como seres humanos com experiências diversas, não somente como alunos dentro do sistema educacional. Em diversos pontos de sua obra, Hooks (2017) destaca a importância de os educadores buscarem conhecer os estudantes, seus medos, angústias, indignações, histórias. Para a autora, uma das maneiras de se construir uma comunidade na sala de aula é o reconhecimento de cada voz individual. Relatos apontam que o slam manteve esse caráter inclusivo no contexto escolar, sendo capaz de dar visibilidade aos alunos e engajando estudantes tímidos, desmotivados, considerados "alunosproblema" e portadores de necessidades especiais.

Tem um aluno que ele é especial, ele tem uma deficiência intelectual. No dia do Slam Interescolar, ele fez a gente chorar. Porque eu falei "eu vou deixar ele se inscrever". Mas eu não sabia que ele escrevia daquele jeito [...] Então, assim, são meninos que a gente nunca tinha parado para ouvir. E é um canal que você acha para escutar. O que esse menino pensa? Qual é a angustia dele? O que ele acha que pode fazer para melhorar? Qual a solução? E você dá informação também. Olha, o slam lá na escola abriu tanta porta, abriu tanta porta... (Maria Felicidade).

Os alunos que são os melhores poetas geralmente vão ser alunos-problema, porque eles são os que refletem sobre a realidade (Eloá).

A autoestima é uma coisa impressionante. A Júlia mesmo era toda retraída. Ela é uma aluna que, no slam, ela floresceu. E hoje ela está uma menina segura e confiante (Dani).

A segurança da estudante, destacada na fala da professora Dani, é vista como fruto da busca por informação na qual os alunos investem no momento de realizar suas produções textuais. Como resultado, alguns relatos apontam a redução do desequilíbrio de poder entre professores e alunos, por exemplo. Nesse caso, assim como na experiência relatada por Hooks (2017) sobre o fomento da diversidade cultural no espaço escolar, a sala de aula deixa de ser, necessariamente, um ambiente harmônico, na medida em que certas verdades e preconceitos são desmascarados. 
Mas o que importa, mano, é você ver o professor ali, um professor racista, na sala de aula, ficar de boca aberta, porque sempre foi acostumado a oprimir aluno e hoje ele não consegue mais, porque esse aluno tem informação e sabe como dialogar com ele (John).

Assim, por mais que os três pontos de discussão encontrem-se imbricados, por fim, chegamos diretamente à discussão acerca do potencial político do slam poetry nas escolas. Nesse sentido, o ponto de partida é: os entrevistados acreditam que, ao dar voz e protagonismo aos alunos, é possível que o slam exerça sua função democratizante também dentro da escola. Hooks (2017) afirma, reincidentemente, que não existe escola neutra: são as preferências políticas que moldam as práticas pedagógicas. Logo, por mais que o slam possa ser articulado com uma diversidade de conteúdos curriculares, as entrevistas revelam que a intenção "mais profunda" daqueles que o levaram para as escolas correspondiam à tentativa de replicação do seu potencial político nesse ambiente. Esse potencial pode ser entendido como a criação de um local democrático de fala, no qual se faz recorrente a representação poética da articulação entre as diversas lutas sociais que caracterizam a busca por uma democracia plural e radical. Os excertos a seguir refletem essa intenção.

Eu queria ampliar essa participação dos alunos. Porque, por exemplo, a gente não tem um grêmio aqui na escola. A gente tem líderes de turma que atuam de vez em quando, falam alguma coisa com as pedagogas, mas isso não é tão efetivo, a meu ver. A participação deles na escola, nas decisões da escola. Então, eles têm poucos espaços de expressão, só algumas coisas (Professora).

[O slam] é uma alternativa de valorizar o meio, porque, geralmente, as escolas não se preocupam com a consciência negra. Então, a gente tem de fazer a valorização dos escritores negros, dos referenciais negros, para que os meninos tivessem, assim, referências positivas então, não só do esporte, não só relacionada à força física, mas na linguagem, na política. Então, nós abrimos esse espaço dentro da escola pública (Érica).

De acordo com essas falas, assim como propõe Gregory (2013), o slam se torna um espaço valioso para grupos que são normalmente silenciados, nesse caso, os próprios estudantes. Além disso, o slam pode operar tanto como exercício de adesão quanto como de crítica à escola. Mouffe (1993) sugere que, para criar essa adesão, é necessária a construção de um conjunto de práticas que criem cidadãos democráticos. Isso não se daria meramente por uma adesão racional, mas, sobretudo, envolvendo paixões e afetos dos alunos.

Percebemos que o slam faz exatamente isso ao propiciar processos de construção de identidades e de identificação política por meio de uma densa implicação dos sujeitos envolvidos. A análise dos relatos sobre os temas das poesias apresentadas nos eventos escolares mostrou que, mesmo dentro do ambiente escolar, as temáticas que tratam de causas sociais continuaram sendo as principais abordadas pelos estudantes. Logo, os estudantes demonstraram engajamento e conhecimento de assuntos de interesse social e o slam permaneceu como esfera de ação cívica e ativismo, como propõe Fields et al. (2014).

Característica marcante que tem é a relação com a polícia, com a ida da polícia nos morros, a abordagem policial [...] Outro tema marcante, a questão da mulher é muito forte. As meninas sempre produzem alguma coisa sobre como os homens agem com elas de maneira inadequada [...] Como seria um Deus negro, teriam a mesma visão de Jesus se ele fosse negro? Mandariam cortar o cabelo? Essas coisas assim. São esses temas principais (Wagner). 
Resistência. Fala sobre racismo. A maioria dos meninos são negros, os poetas. Fala sobre essa questão. Machismo também, as meninas falam (Professora).

Observam-se, então, temas semelhantes àqueles relatados por Neves (2017) e também observados por nós em "slams de rua" brasileiros. Mesmo no caso de uma das escolas, em que os temas foram previamente determinados, os alunos mantiveram aqueles relacionados às lutas sociais com as quais se identificam.

Então, primeira fase a gente deixou livre para ter adesão e a segunda e a terceira fases nós tivemos um tema. Na segunda fase, foi a escola. Então, falar sobre alguma coisa que envolvesse a escola, e o terceiro foi o lugar onde a gente vive, que inclusive foi o tema da última Olimpíada de Português. [...] Mesmo na segunda e terceira fase, esse aluno da escola, ele falava o quê?? Falava da homossexualidade na escola. Então, essa característica do slam de denúncia, de espaços políticos e de discutir questões que estão fora da escola continuou. Independente do tema (Camila).

No caso anterior, as professoras também adaptaram os critérios de avaliação das poesias de acordo com aqueles utilizados nas Olimpíadas de Língua Portuguesa. Em algumas escolas, o corpo de jurados foi composto majoritariamente por professores, o que fere o critério aleatório de escolha dos jurados e, certamente, reduz a dimensão democratizante do slam. Aqui, percebe-se uma conexão com as constatações de Émery-Bruneau e Yobé (2014) de que as avaliações das performances do slam, quando esse é levado para o ambiente escolar, podem passar a responder aos critérios validados nesse ambiente, não àqueles normalmente utilizados na prática social. Essas questões demarcam diferenças no slam ao ser levado de um espaço para outro. Contudo, o aspecto mais problemático relacionado à transposição do slam para o espaço escolar foi percebido por uma professora e reafirmado por alunos que competem nos dois ambientes - escola e rua. Eles observaram que as performances dos alunos foram mais "tensas" quando no ambiente escolar, diferentemente daquilo que eles próprios apresentavam anteriormente nas ruas.

Sinceramente, foi literalmente arrancar uma coisa que estava na rua e colocar dentro do espaço institucional. Ela já estava acontecendo na rua, eles já eram brilhantes na rua, só que eles se sentiam acuados na escola. Tanto que, nas filmagens, na competição dentro da escola, eu não considero que a performance deles foi uma performance boa, em vista da performance que eu vejo eles tendo na rua. Então, eu sinto que realmente o espaço institucional, ele restringe essa liberdade, essa forma de se portar, de se colocar do poeta. [...] O espaço escolar, ele é um espaço podador. Palavrão pode, não pode, não pode isso, não pode aquilo. Se você começa a limitar, já na própria concepção, evitando tal palavra ou tal ideologia, você já está matando a essência da arte, que é a liberdade. Então, eu acho que é muito isso que acontece na escola (Eloá).

Eu acho que, na escola, mano, tem aquele certo medo de falar algumas coisas, de você criticar algum ponto que as pessoas que venham a te falar coisas que acham que você está errado. Quando a pessoa vem te falar que você está errado por você criticar aquele ponto, que talvez seja uma coisa que a outra pessoa defende. Aí entra o negócio da hierarquia, que uma pessoa com a hierarquia maior que a sua vai te falar algumas coisas e a maioria você vai acreditar, por ela ser maior que você, por ela ser mais estudada que você, e faz você acreditar que ela tá certa e você tá errado [...] O slam na rua, ele te dá muito mais autonomia de você falar, eu vejo como essa forma. $\mathrm{Na}$ 
rua, você fala o que você pensa, você grita, você xinga, você faz o que você quiser, mano. É o seu ponto de vista, ninguém tem nada contra isso (Pedro).

A escola acaba retraindo muito os alunos. Quando o slam é na rua, as pessoas lá, tanto público, tanto os competidores costumam expor mais aquilo que eles pensam. A escola... é pelo ambiente mesmo. Não só a escola, em qualquer ambiente institucional, quando ocorre slam em ambientes fechados assim, os poetas costumam se sentir mais presos, porque eles sentem que aquele não é o local deles. Então, quando esses movimentos acontecem na escola, muitas vezes, as palavras ficam retraídas. Na escola, os alunos que retraem por medo assim, "eu vou falar sobre racismo, mas não de forma tão agressiva, porque se eu falar de uma forma agressiva eles vão achar que eu estou me vitimizando" (Ira).

É possível interpretar que essa tensão decorra, ao menos em parte, do fato de que os slammers, que, na rua, falam para um público específico, que escolhe estar lá e normalmente é empático com suas lutas, dentro da escola são confrontados com um público mais diverso. Young (2000) destaca que membros de um público plural, no que diz respeito a experiências, histórias de vida, comprometimentos, ideais, interesses e objetivos, ao se comunicarem uns com os outros, sabem que podem ser respondidos por essa pluralidade, de modo que o acesso que os outros têm aos seus pontos de vista os tornam cuidadosos na hora de se expressarem. Assim, pode-se analisar que, embora o ambiente escolar fira alguns princípios que formam o slam das ruas, por outro lado, propicia confrontação maior com a realidade social concreta, na medida em que não cria um público ideal distante das instituições. Portanto, a escola traz elementos desafiadores à prática do slam.

Além disso, é importante demarcar que existem duas camadas de instauração do antagonismo por meio do slam poetry. Uma é interna, a partir do jogo proposto, da tematização de temas difíceis, da confrontação via competição, do estabelecimento de um ganhador e perdedores etc. Nessa camada, são os indivíduos que se confrontam e constituem sujeitos políticos. Contudo, existe ainda outra camada, que é dada na medida em que o próprio slam, como prática estranha à instituição escolar, desafia-a e a confronta. Nessa camada, é a instituição que está em jogo, sendo provocada, desafiada e criticada. Assim, mesmo quando o diretor diz que, em determinada escola, não se trabalha com arte, impedindo a realização do slam, ali a sua proposição cumpriu papel de desmascarar a posição das lideranças institucionais, criando uma posição contra a qual se pode lutar. Da mesma maneira, a possibilidade de uma acusação de "vitimismo" (como colocada em uma das falas anteriores), que apresenta efeito psicológico capaz de restringir o discurso dos poetas, se concretizada, também significaria a emersão de um sentimento que existiria independentemente do slam, mas que, sem ele, talvez ficasse latente, sem que se pudesse, portanto, confrontá-lo. A verdade é que, ao ser levado ao ambiente escolar, o slam expande seu potencial agonístico em função da pluralidade dos públicos, que passam a ter a possibilidade de participar dele.

Dentro da perspectiva de uma democracia radical de Mouffe (1993; 2015), a tensão e o conflito não são elementos ruins, que deveriam ser banidos da democracia. Pelo contrário: se há uma possibilidade de democratizar a sociedade, a política e a escola, ela está na percepção do conflito como algo inerente ao pluralismo. Ao propor uma ritualização e uma espécie de jogo, o slam produz um mecanismo de conversão dos antagonismos em agonismos, conforme a proposta de Mouffe. Ou seja, permite que as diferenças existam e que as exclusões sociais, opressões e dominações sejam expostas, mas estabelece um princípio de respeito, no qual os antagonismos devem respeitar as regras estabelecidas.

Entretanto, reconhecer que as formas de arte crítica representam uma importante dimensão na política democrática não significa que elas possam, sozinhas, realizar as transformações necessárias para o 
estabelecimento de uma nova hegemonia (MOUFFE, 2007). Uma extensão desse argumento permite afirmar que não se pode esperar que a abertura ao slam poetry, por si só, seja capaz de transformar o ambiente escolar por completo. Esse último continuará a ser espaço de controle, e isso afetará a maneira como o slam é desempenhado nesse local. É nesse sentido que Mouffe (2007) afirma ser necessário abandonar a ilusão modernista que confere um local privilegiado aos artistas, conjuntamente com a concepção revolucionária de política que acompanha esse local.

Mesmo diante dessas questões, não é possível afirmar que o potencial político do slam poetry se perde com a sua transposição para o ambiente escolar. Ele ainda se enquadra no conceito de Mouffe (2007) de arte crítica, ao criar um espaço no qual os artistas podem subverter a hegemonia dominante e construir novas subjetividades. Assim, mesmo que a escola pareça se apropriar do potencial educacional do slam, conforme sugere a hipótese de Poole (2007), ele também é levado a ela no intuito de replicar seu potencial; ou seja, em troca, o slam se apropria da escola para expandir sua área de influência e o alcance de ideologias que agora já lhe parecem naturais.

\section{Considerações Finais}

A escola tem constituído, nos últimos anos, o lócus de diversas manifestações de protesto. Desde os protestos de 2013, no Brasil, que, em muitos lugares, passaram pelas escolas, até o fenômeno das ocupações de escolas públicas, em 2016, os estudantes brasileiros vêm protagonizando um processo de questionamento dessa instituição. O slam poetry, ainda que não seja um fenômeno gerado no Brasil, faz parte desse processo. Não obstante, sua institucionalização, em diversas iniciativas escolares, agrega uma característica especial a esse processo, na medida em que confere um papel importante também aos professores, os quais, como observamos, são, em grande parte, responsáveis pela extensão dessa prática social para dentro da escola. Desse modo, o presente artigo buscou analisar como têm sido os processos de inserção do slam poetry em escolas do estado do Espírito Santo, bem como os resultados dessa transposição.

Nossa análise apontou que, em seis escolas, o slam poetry foi bem-recebido e/ou incentivado pela comunidade escolar de modo geral. Nos outros dois casos, houve resistência por parte de coordenadores e diretores. Os relatos apontam que a abertura ao slam poetry pode estar ligada a fatores internos, como a parceria entre professores, a liberdade proporcionada a eles pela direção e a prévia realização de manifestações artísticas na escola, além de fatores externos, como a inserção em uma comunidade na qual ocorrem atividades culturais. Por outro lado, a resistência ao slam pode estar ligada à discrepância entre as vivências dos coordenadores e diretores escolares e as realidades dos locais nos quais as escolas estão inseridas. Além disso, é possível que atividades como o slam poetry sejam vistas como contestadoras do poder disciplinar que rege as instituições de ensino e, consequentemente, taxadas, por alguns membros da comunidade escolar, de desordeiras.

Sobre suas potencialidades no ambiente educacional, o slam parece se articular com conteúdos diversos trabalhados na área de linguagens, desde a óbvia conexão com a poesia e com a literatura até aulas sobre ortografia. Sua articulação depende da criatividade do professor que o leva à sala de aula, já que essa transposição é feita de modo informal (sem constar no conteúdo oficial das disciplinas). Os relatos apontam que o slam tem sido capaz de aumentar o engajamento dos alunos, inclusive daqueles taxados como "alunosproblema", normalmente desmotivados, ou invisibilizados de outras maneiras. O slam promove, na escola, o reconhecimento que alguns estudantes poetas já conquistaram nas ruas e permite que membros da comunidade escolar conheçam os alunos participantes de modo mais profundo, em suas vivências, angústias, motivações etc.

O estudo também demonstra que, apesar de instrumentalizarem o slam para o ensinamento de 
conteúdos diversos, aqueles que o levam para as escolas o fazem com a intenção de que essa ação seja capaz de democratizar o espaço escolar. Além da expectativa de dar voz aos estudantes, espera-se que problemas sociais presentes nas comunidades e na sociedade de modo mais amplo - como o racismo, o sexismo, a violência e outros - possam ser abordados no espaço escolar, além de ser esperado, também, fomento a reflexões acerca desse próprio espaço. Embora ocorram algumas descaracterizações do slam quando esse entra em contato com a escola, o espaço de expressão criado e os temas das poesias feitas pelos estudantes parecem demonstrar que seu potencial político se realiza também nesse ambiente. Pode-se afirmar que, na escola, o slam se mantém como arte crítica (MOUFFE, 2007) e como um veículo para a democracia radical e plural (MOUFFE, 1993). No entanto, a escola traz elementos desafiadores ao slam, ao confrontá-lo com regras e práticas que se opõem ao ideal desses espaços de prática artística livre e não institucional. De modo geral, se, por um lado, tem-se a hipótese de Poole (2007) de que o slam pode ser apropriado culturalmente pelo establishment, ávido a explorar o seu potencial educacional e sociopolítico, por outro lado, este estudo aponta que o próprio movimento do slam poetry tem buscado se apropriar do espaço escolar com o objetivo de expandir sua rede de influência e sua ideologia política.

Por fim, as limitações deste estudo encontram-se, principalmente, na restrição ao contexto estadual e em não ouvir as percepções dos estudantes de maneira mais ampla (restringindo-se a dois estudantes que já atuavam como slammers nas ruas) acerca desse processo de transposição do slam poetry para o ambiente escolar. Devem ser consideradas, também, as limitações dos métodos de pesquisa aqui aplicados, que não permitem generalizações empíricas dos resultados. A aplicação dessa pesquisa em outros contextos, a inclusão dos estudantes em seu escopo e a exploração de pontos aqui levantados por meio de outros métodos se revelam, assim, possibilidades para pesquisas futuras.

\section{Contribuição dos Autores}

Problematização e conceitualização: Silva, C. R.; Metodologia: Silva, C. R.; Losekann, C.; Análise: Silva, C. R.; Losekann, C.; Redação: Silva, C. R.; Losekann, C.

\section{Notas}

1. De acordo com matéria da Folha de S. Paulo, existem, atualmente, no Brasil, 210 grupos de slam. Disponível em: https://www1. folha.uol.com.br/colunas/bruno-molinero/2019/12/brasil-tem-210-grupos-de-slam-diz-torneio-nacional-de-poesia-falada. shtml. Acesso em: 4 fev. 2020.

2. Esta entrevistada preferiu não ser identificada nesta pesquisa.

3. O site encontrava-se indisponível quando da publicação deste artigo.

\section{Referências}

AMARAL, M. T. O rap, o hip-hop e o funk: A "eróptica” da arte juvenil invade a cena das escolas públicas nas metrópoles brasileiras. Psicologia USP, v. 22, n. 3, p. 593-620, 2011. 
AMARAL, M. T. O rap, a revolução e a educação: Do Bronx à Primavera Árabe. Ide, São Paulo, v. 36, n. 56, p. $145-159,2013$.

AMARAL, M. T.; SANTOS, V. S. Capoeira, herdeira da diáspora negra do Atlântico: De arte criminalizada a instrumento de educação e cidadania. Revista do Instituto de Estudos Brasileiros, v. 62, p. 54-73, 2015. http://doi.org/10.11606/issn.2316-901X.v0i62p54-73

ATERIANUS-OWANGA, A. 'Orality is my reality': The identity stakes of the 'oral' creation in Libreville hiphop practices. Journal of African Cultural Studies, v. 27, n. 2, p. 146-158, 2015. https://doi.org/10.1080/13 696815.2014 .987222

AUYERO, J. Los sinuosos caminos de la etnografía política. Pléyade, n. 10, p. 15-36, 2012.

BELLE, F. The poem performed. Oral Tradition, v. 18, n. 1, p. 14-15, 2003. https://doi.org/10.1353/ ort.2004.0007

BOUDREAU, K. E. Slam poetry and cultural experience for children. Forum on Public Policy Online: A journal of the Oxford round table, v. 8, n. 1, p. 1-15, 2009.

BROWN, R. Promoting cooperation and respect: "Bad" poetry slam in the nontraditional classroom. Pedagogy: Critical approaches to teaching literature, language, composition, and culture, v. 11, n. 3, p. 571590, 2011. https://doi.org/10.1215/15314200-1302804

CULLELL, D. (Re-)Locating prestige: Poetry readings, poetry slams, and poetry jam sessions in contemporary Spain. Hispanic Research Journal, v. 16, n. 6, p. 545-559, 2015. https://doi.org/10.1080/14682737.2015.11 29837

ÉMERY-BRUNEAU, J. Le slam: Émergence fulgurante de cette pratique sociale. Quel souci de sa transposition didactique? La lettre de l'AIRDF, n. 58, p. 24-28, 2015.

ÉMERY-BRUNEAU, J.; YOBÉ, V. El slam em Québec: De práctica social a objeto de enseñanza. Impossibilia, n. 8, v. 1, p. 247-268, 2014.

FANON, F. Pele negra, máscaras brancas. Salvador: Edufba, 2008.

FIELDS, A. et al. Youth voices and knowledges: Slam poetry speaks to social policies. Sexuality Research and Social Policy, v. 11, n. 4, p. 310-321, 2014. https://doi.org/10.1007/s13178-014-0154-9

FOUCAULT, M. Vigiar e punir: Nascimento da prisão. Petrópolis: Vozes, 1999.

GLAZNER, G. M. Poetry slam: The competitive art of performance poetry. San Francisco: Manic D Press, 2000.

GREGORY, H. Youth take the lead: Digital poetry and the next generation. English in Education, v. 47, n. 2, p. 118-133, 2013. https://doi.org/10.1111/eie.12011

HOOKS, B. Ensinando a transgredir: A educação como prática da liberdade. São Paulo: Editora WMF Martins Fontes, 2017.

MOUFFE, C. The return of the political. London: Verso, 1993.

MOUFFE, C. Artistic activism and agonistic spaces. Art \& Research: a journal of ideas, contexts, and 
methods, v. 1, n. 2, p. 1-5, 2007.

MOUFFE, C. Sobre o politico. São Paulo: Editora WMF Martins Fontes, 2015.

NEVES, C. A. B. Slams - Letramentos literários de reexistência ao/no mundo contemporâneo. Linha D’Água, v. 30, n. 2, p. 92-112, 2017. https://doi.org/10.11606/issn.2236-4242.v30i2p92-112

POETRY SLAM INC. 2016-17 Season Annual Report, 2019. Disponível em: https://poetryslam.com/ about/2015-annual-report/3.Acesso em: 03 jun. 2019.

POOLE, S. 'Slambiguité? Youth culture and the positioning of 'Le Slam" in France. Modern \& Contemporary France, v. 15, n. 3, p. 339-350, 2007.

POOLE, S. Le texte, autrement. Opening the (language classroom) door to slam. The French Review, v. 82, n. 2, p. 293-305, 2008. https://doi.org/10.2307/25481547

RIBEIRO, D. O que é lugar de fala? Belo Horizonte: Letramento, 2017.

SMITH, M. K.; KRAYNAK, J. Take the mic: The art of performance poetry, slam, and the spoken word. Naperville: Sourcebooks MediaFusion, 2009.

SOMERS-WILLET, S. B. A. Slam poetry and cultural politics of performing identity. The Journal of the Midwest Modern Language Association, v. 38, n. 1, p. 51-73, 2005.

SPOSITO, M. P.; ANDRADE, C. L.; NASCIMENTO, G. Memória do movimento popular de arte no bairro de São Miguel: Cultura, arte e educação. São Paulo: USP/FFCL, 1987.

VIANA, L. Poetry slam na escola: Embate de vozes entre tradição e resistência. 2018. 165 f. Dissertação (Mestrado Profissional em Letras). - Universidade Estadual Paulista (UNESP), Faculdade de Ciências e Letras, Assis, 2018.

YOUNG, I. M. Inclusion and Democracy. New York: Oxford University Press, 2000.

\section{Sobre os Autores}

CaIo Ruano da SiLVA é mestre em Ciências Sociais pela Universidade Federal do Espírito Santo (UFES). Mestre e graduado em Administração pela UFES. Especialista (MBA) em Gerenciamento de Projetos pela Fundação Getúlio Vargas (FGV). Professor no Instituto Federal do Espírito Santo (IFES)

Cristiana LoseKann é doutora em Ciência Política pela Universidade Federal do Rio Grande do Sul (UFRGS). Professora da Universidade Federal do Espírito Santo (UFES) e Professora Permanente do Programa de Pósgraduação em Ciências Sociais da UFES. Bolsista produtividade em pesquisa do CNPQ nível 2. 